\title{
Associations between autoantibodies against apolipoprotein B-100 peptides and vascular complications in patients with type 2 diabetes
}

\author{
G. N. Fredrikson • D. V. Anand • D. Hopkins • \\ R. Corder • R. Alm • E. Bengtsson • P. K. Shah • \\ A. Lahiri • J. Nilsson
}

Received: 3 March 2009 / Accepted: 1 April 2009 / Published online: 12 May 2009

(C) The Author(s) 2009. This article is published with open access at Springerlink.com

\begin{abstract}
Aims/hypothesis Oxidation of LDL in the arterial extracellular matrix is a key event in the development of atherosclerosis and autoantibodies against oxidised LDL antigens reflect disease severity and the risk of developing acute cardiovascular events. Since type 2 diabetes is associated with increased oxidative stress, we tested the hypothesis that autoantibodies against oxidised LDL antigens are biomarkers for vascular complications in diabetes. Methods We studied 497 patients with type 2 diabetes without clinical signs of coronary heart disease. Oxidised LDL autoantibodies were determined by ELISA detecting IgG and $\operatorname{IgM}$ specific for native and malondialdehyde (MDA)-modified apolipoprotein B-100 peptides p45 and p210. The severity of coronary disease was assessed as the coronary artery calcium score.

Results Patients affected by retinopathy had significantly higher levels of IgG against MDA-p45 and MDA-p210. In contrast, high levels of autoantibodies against the
\end{abstract}

corresponding native peptides were associated with less coronary calcification and a lower risk of progression of coronary disease.

Conclusions/interpretation Our observations suggest that LDL oxidation is involved in the pathogenesis of diabetic retinopathy and that autoantibodies against apolipoprotein B peptides may act as biomarkers for both micro- and macrovascular complications in diabetes.

Keywords Antibodies - Low-density lipoprotein · Oxidation · Peripheral neuropathy $\cdot$ Retinopathy
Abbreviations
Apo Apolipoprotein
CAC Coronary artery calcium
CRP C-reactive protein
MDA Malondialdehyde
MPS Myocardial perfusion scintigraphy
IMT Intima-media thickness

G. N. Fredrikson · R. Alm • E. Bengtsson · J. Nilsson $(\triangle)$

Department of Clinical Sciences, Malmö University Hospital, Lund University,

CRC Entrance 72, 91:12,

20502 Malmö, Sweden

e-mail: jan.nilsson@med.lu.se

G. N. Fredrikson

Department of Biomedical Laboratory Science and Technology, Malmö University,

Malmö, Sweden

D. V. Anand · A. Lahiri

Cardiac Imaging and Research Center, Wellington Hospital,

London, UK

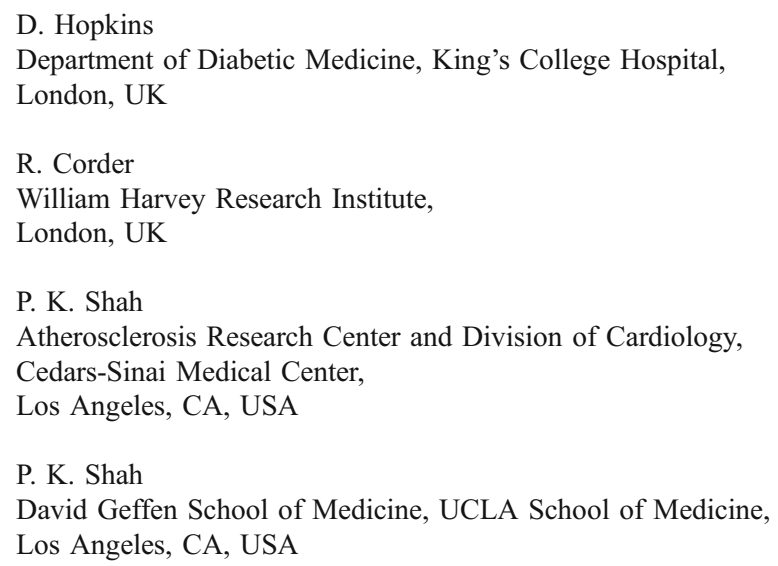




\section{Introduction}

The role of immune responses against modified selfantigens in atherosclerosis has attracted increasing attention during recent years [1, 2]. Hypercholesterolaemic mice deficient in components of the innate [3, 4] and adaptive [5-8] immune systems are generally characterised by decreased plaque formation, suggesting that immune responses against self-antigens modified by hypercholesterolaemia are pro-atherogenic. Oxidised LDL is considered the most important self-antigen generated by hypercholesterolaemia and autoantibodies against oxidised LDL are abundant in both hypercholesterolaemic animals and in humans [9-11]. However, unexpected findings of decreased atherosclerosis development in hypercholesterolaemic animals immunised with oxidised LDL have demonstrated that atheroprotective immune responses also exist [12-16]. Collectively, these studies imply that the initiation and progression of atherosclerosis is modulated by the balance between protective and pro-atherogenic immunity [17].

The immunogenic properties of oxidised LDL depend on the formation of oxidised phospholipids, fragmentation of the LDL protein apolipoprotein (Apo) B-100 and the aldehyde modification of these Apo B fragments [10, 18]. We have previously identified several native and aldehyde-modified ApoB peptide sequences that are targeted by autoimmune responses in humans [19]. Immune responses against the ApoB amino acids 661-680 (p45) and 3136-3155 (p210) have been found to be of particular importance and pilot vaccines based on these peptides significantly inhibit the development of atherosclerosis in experimental animals [20, 21]. People with high levels of IgG against the native forms of p45 [22] and p210 [23] have a lower risk of development of acute myocardial infarction, whereas high levels of IgM against aldehyde-modified p45 and p210 are associated with more advanced carotid atherosclerosis [19, 24]. An inverse relation between $\operatorname{IgG}$ against native p210 and the severity of coronary atherosclerosis has also been reported recently [23].

Type 2 diabetes is associated with both increased vascular oxidative stress and the presence of LDL with increased susceptibility to oxidation [25]. However, the possible relations between autoimmune responses to modified selfantigens in oxidised LDL and vascular disease in diabetes remain largely unexplored. The aim of the present study was to determine whether there is an association between autoantibodies against the ApoB antigens p45 and p210 and vascular complications in patients with type 2 diabetes.

\section{Methods}

Patients The participants in the present analysis were derived from a cohort of type 2 diabetic patients without history or symptoms of coronary heart disease who were participating in a study of the ability of coronary calcium score to predict silent myocardial ischaemia and short-term cardiovascular events [26]. Patient recruitment, inclusion and exclusion criteria have been reported previously [26]. The study patients were prospectively recruited from four diabetes clinics in secondary care. The study was approved by the local research ethics committees of participating institutions and the Administration of Radioactive Substances Advisory Committee and all participants gave informed consent. A total of 510 individuals were prospectively enrolled in the study. Symptoms of peripheral neuropathy were recorded and sensation (using a $10 \mathrm{~g}$ monofilament) and knee and ankle reflexes were assessed. Retinopathy was assessed by annual retinal examination according to national guidelines [27]. Fasting blood and urine samples were obtained for DCCT-aligned $\mathrm{HbA}_{1 \mathrm{c}}$, lipid profile, urea, creatinine and the urine albumin/ creatinine ratio. Microalbuminuria was defined as a urine albumin/creatinine ratio $>2.5 \mathrm{mg} / \mathrm{mmol}$ for men and $>3.5 \mathrm{mg} / \mathrm{mmol}$ for women.

Coronary calcium imaging and myocardial perfusion scintigraphy The protocol for coronary artery calcium (CAC) imaging and myocardial perfusion scintigraphy (MPS) have been described previously [28]. In the present study CAC scores were classified into two categories: low to moderate coronary calcification ( $\leq 400$ Agatston units) and severe to extensive ( $>400$ Agatston units) [28, 29]. MPS was performed according to a 2 day stress-rest ${ }^{99 \mathrm{~m}}$ Tc-sestamibi protocol using symptom-limited treadmill exercise.

ELISA against the malondialdehyde-modified ApoB-100 peptide Polypeptide corresponding to the amino acids 661680 in human ApoB-100 (p45; IEIGLEGKGFEPT LEALFGK) and the 3136-3155 amino acid sequence of human ApoB-100 (p210; KTTKQSFDLSVKAQYKK NKH) were synthesised (KJ Ross Petersen, Horsholm, Denmark) and modified by $0.5 \mathrm{~mol} / 1$ malondialdehyde (MDA) for $3 \mathrm{~h}$ at $37^{\circ} \mathrm{C}$. They were subsequently used in ELISAs for the determination of peptide-specific antibodies, as described previously [19].

Statistical analysis Differences regarding baseline characteristics were tested with the $t$ and $\chi^{2}$ tests, as applicable. Skewed variables were log-transformed before statistical tests. Student's $t$ test was used to test for the significance of differences between group means. Spearman correlation coefficients were used to examine relationships among continuous variables. A logistic regression model was used to determine independent associations of various risk factors with retinopathy, peripheral neuropathy and coro- 
nary calcification. A $p$ value of $<0.05$ was considered significant.

\section{Results}

The patients included in the present analysis were recruited from a cohort of patients with type 2 diabetes participating in a study of the ability of coronary calcium score to predict silent myocardial ischaemia and short-term cardiovascular events [26]. Of the original 510 individuals enrolled, 13 were excluded from the present study because plasma samples were no longer available. Of the remaining 497 diabetic patients, 114 (22.9\%) had retinopathy, 90 (18.1\%) had peripheral neuropathy and 71 (14.4\%) had microalbuminuria. Since patients with clinically manifest coronary artery disease, cerebrovascular disease or peripheral artery disease were excluded from the initial study, we used coronary calcium scores and ischaemia as assessed by myocardial perfusion scintigraphy as surrogate markers for diabetic macrovascular complications. The clinical characteristics of the study cohort have been published previously $[26,30]$.

Autoantibodies against native and MDA-modified ApoB peptides p45 and p210 were detected by custom-made ELISAs. The highest antibody levels were found against the p210 peptide. Antibody levels against MDA-modified peptides were generally higher than against the corresponding native peptide. This was particularly evident for $\mathrm{p} 210$, for which both IgG and IgM levels were threefold higher for the MDA peptide (Fig. 1).

Autoantibodies against ApoB peptides and microvascular complications Patients with retinopathy had significantly higher levels of IgG against MDA-p45 and MDA-p210 than patients without retinopathy (Fig. 2). They also had significantly higher levels of IgG against native p210 and a
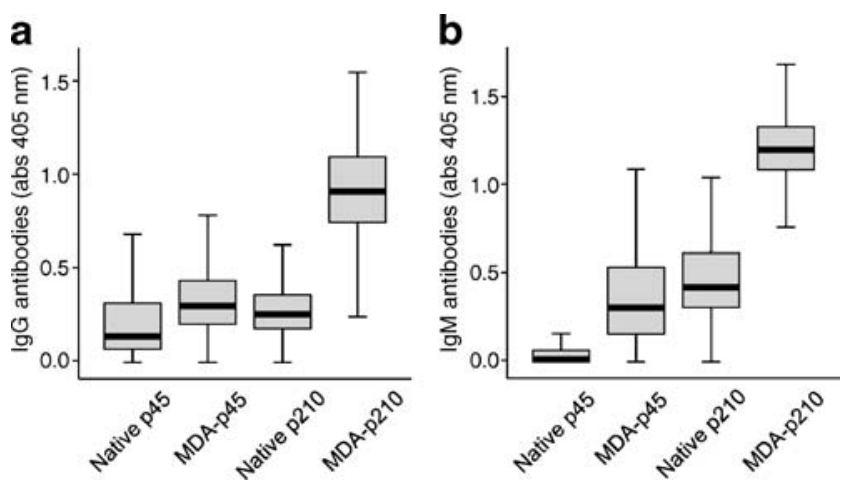

Fig. 1 Box plots showing plasma levels (absorbance [abs] units measured at $405 \mathrm{~nm}$ ) of a IgG and b IgM against native and MDAmodified ApoB peptides p45 and p210 in the study cohort
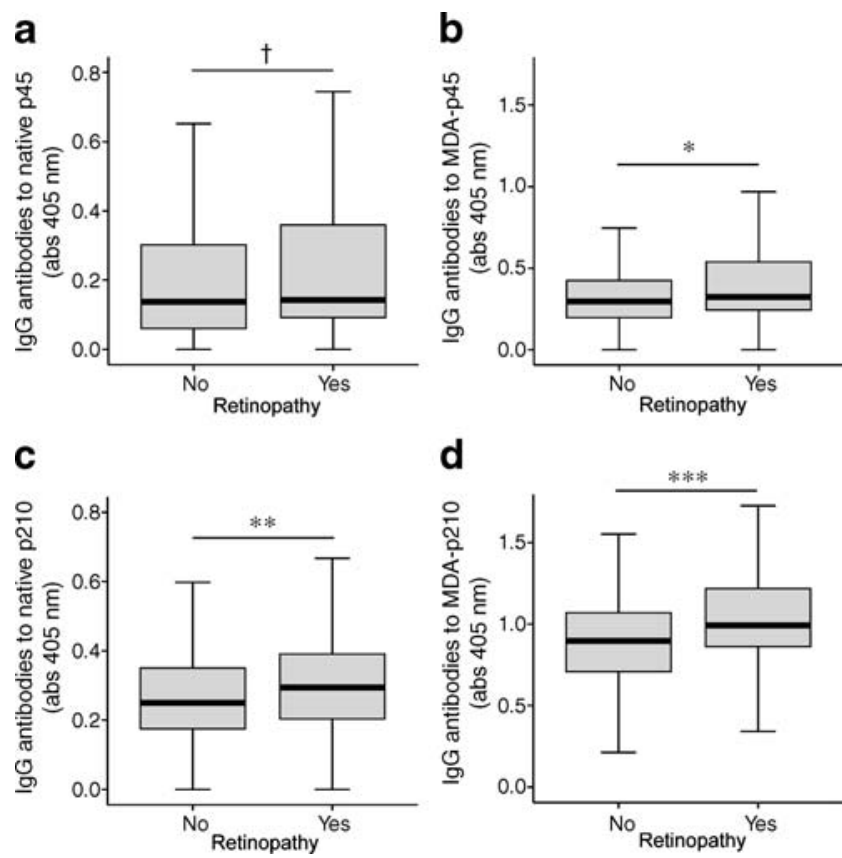

Fig. 2 Box plots showing plasma levels of IgG (absorbance [abs] units measured at $405 \mathrm{~nm}$ ) against a native $\mathrm{p} 45$, b MDA-p45, c native p210 and d MDA-p210 in diabetic individuals with and without retinopathy. $\dagger p<0.1, * p<0.05, * * p<0.01, * * * p<0.001$

similar trend could be observed for IgG against native $\mathrm{p} 45$ (Fig. 2). There were no differences in p45 or p210 IgM levels between patients with and without retinopathy (data not shown). Compared with patients without retinopathy, patients who had developed retinopathy were older, had a longer duration of diabetes, increased $\mathrm{HbA}_{1 \mathrm{c}}$, had a moderately elevated HDL-cholesterol level and were more frequently on insulin treatment (Table 1). When all of these variables were entered into a logistic regression model, MDA-p210 IgG ( $\beta$ coefficient 1.98, $p<0.001)$, age ( $\beta$ coefficient $0.04, p=0.005)$, duration of diabetes ( $\beta$ coefficient $0.06, p=0.001)$ and $\mathrm{HbA}_{1 \mathrm{c}}$ level $(\beta$ coefficient $0.22, p=0.001$ ) remained as independent predictors of the presence of retinopathy. To further control for the possible influence of the duration of diabetes we restricted the analysis to subjects with duration of disease less than 10 years $(n=333)$. Increased levels of MDA-p210 IgG were found in patients with retinopathy $(n=53)$ also in this subgroup ( $1.05 \pm 0.24$ vs $0.89 \pm 0.26$ absorbance units, $p<0.001)$.

MDA-p210 IgG levels increased with age, blood pressure and LDL level (Table 2). High levels of MDAp210 IgG were also associated with low triacylglycerol and HDL-cholesterol levels, unexpectedly suggesting that antibody levels are increased in states of good metabolic control. However, there was no association between the MDA-p210 IgG and $\mathrm{HbA}_{1 \mathrm{c}}$ level or the duration of diabetes. 
Table 1 Clinical characteristics of diabetic patients with and without retinopathy

Values are mean $\pm \mathrm{SD}$ or percentage

\begin{tabular}{lllc}
\hline Characteristic & No retinopathy $(n=383)$ & Retinopathy $(n=114)$ & $p$ value \\
\hline Age & $52.2 \pm 8.2$ & $55.2 \pm 8.3$ & $<0.001$ \\
Male sex (\%) & 60.6 & 61.4 & 0.87 \\
Duration of diabetes (years) & $7.4 \pm 5.7$ & $10.4 \pm 6.5$ & $<0.001$ \\
HbA $_{1 \mathrm{c}}(\%)$ & $8.1 \pm 1.6$ & $8.6 \pm 1.6$ & 0.001 \\
BMI $\left(\mathrm{kg} / \mathrm{m}^{2}\right)$ & $28.5 \pm 4.8$ & $28.5 \pm 5.4$ & 0.97 \\
Systolic BP $(\mathrm{mmHg})$ & $136 \pm 16$ & $138 \pm 18$ & 0.29 \\
Diastolic BP $(\mathrm{mmHg})$ & $83 \pm 12$ & $85 \pm 14$ & 0.15 \\
Total cholesterol $(\mathrm{mmol} / \mathrm{l})$ & $4.8 \pm 0.9$ & $4.8 \pm 1.0$ & 0.99 \\
LDL-cholesterol $(\mathrm{mmol} / \mathrm{l})$ & $2.7 \pm 0.8$ & $2.7 \pm 0.9$ & 0.94 \\
HDL-cholesterol $(\mathrm{mmol} / \mathrm{l})$ & $1.2 \pm 0.4$ & $1.4 \pm 0.4$ & 0.019 \\
Triacylglycerol $(\mathrm{mmol} / \mathrm{l})$ & $1.9 \pm 1.1$ & $1.8 \pm 1.2$ & 0.33 \\
C-reactive protein $(\mathrm{mg} / \mathrm{l})$ & $8.2 \pm 33.2$ & $8.1 \pm 14.8$ & 0.98 \\
Current smokers $(\%)$ & 20.9 & 14.0 & 0.17 \\
Insulin therapy $(\%)$ & 18.5 & 29.8 & 0.01 \\
Statin therapy $(\%)$ & 39.9 & 36.8 & 0.55 \\
\hline
\end{tabular}

There were no differences in autoantibodies against $\mathrm{p} 45$ and p210 in patients with or without microalbuminuria.

Autoantibodies against ApoB peptides and coronary heart disease Patients were stratified as having low to moderate ( $\leq 400$ Agatston units, $n=438$ ) or severe to extensive ( $>400$ Agatston units, $n=59$ ) coronary calcification [28]. Patients with low to moderate coronary calcification had higher plasma levels of both $\operatorname{IgG}$ and $\operatorname{IgM}$ against native p45 $(0.26 \pm 0.31$ vs $0.19 \pm 0.23$ absorbance units, $p<0.05$, and $0.062 \pm 0.11$ vs $0.048 \pm 0.111$ absorbance units, $p=$ 0.005 , respectively) and native p210 $(0.29 \pm 0.174$ vs $0.24 \pm$ 0.14 absorbance units, $p<0.01$, and $0.48 \pm 0.24$ vs $0.39 \pm$ 0.18 absorbance units, $p=0.005$, respectively; Fig. 3). When we controlled for age, systolic blood pressure, duration of diabetes, LDL cholesterol, HDL cholesterol, triacylglycerol and $\mathrm{HbA}_{1 \mathrm{c}}$ in a logistic regression analysis,
Table 2 Correlations between risk factors and plasma levels of IgG against p45 and p210

Values are Spearman rank correlation coefficients $* p<0.05 ; * * p<0.01 ; \dagger p<0.005$

\begin{tabular}{|c|c|c|c|c|}
\hline \multirow[t]{2}{*}{ Variable } & \multicolumn{4}{|c|}{ Antibody } \\
\hline & $\mathrm{p} 45$ & MDA-p45 & P210 & MDA-p210 \\
\hline Age (years) & -0.01 & 0.03 & 0.06 & $0.12 * *$ \\
\hline Duration of diabetes (years) & 0.04 & 0.01 & 0.01 & -0.05 \\
\hline $\mathrm{HbA}_{1 \mathrm{c}}(\%)$ & 0.05 & -0.01 & -0.02 & -0.07 \\
\hline BMI $\left(\mathrm{kg} / \mathrm{m}^{2}\right)$ & -0.06 & -0.02 & 0.01 & 0.02 \\
\hline Systolic BP (mmHg) & 0.03 & 0.04 & 0.02 & $0.09 *$ \\
\hline Diastolic BP (mmHg) & 0.07 & 0.07 & 0.02 & $0.13 \dagger$ \\
\hline Total cholesterol (mmol/1) & 0.00 & 0.02 & 0.00 & 0.08 \\
\hline LDL-cholesterol (mmol/l) & 0.02 & 0.01 & 0.05 & $0.11^{*}$ \\
\hline HDL-cholesterol (mmol/l) & -0.02 & 0.03 & $0.12 *$ & $0.16^{* *}$ \\
\hline Triacylglycerol (mmol/l) & 0.01 & 0.33 & $-0.16 \dagger$ & $-0.14 \dagger$ \\
\hline C-reactive protein $(\mathrm{mg} / \mathrm{l})$ & 0.01 & 0.01 & 0.01 & -0.01 \\
\hline
\end{tabular}


Table 3 Clinical characteristics of diabetic patients with and without peripheral neuropathy

Values are mean $\pm \mathrm{SD}$ or percentage

\begin{tabular}{|c|c|c|c|}
\hline Characteristic & No neuropathy $(n=407)$ & Neuropathy $(n=90)$ & $p$ value \\
\hline Age (years) & $52.4 \pm 8.5$ & $53.9 \pm 7.9$ & 0.14 \\
\hline Male sex $(\%)$ & 60.4 & 62.2 & 0.75 \\
\hline Duration of diabetes (years) & $7.8 \pm 5.7$ & $9.2 \pm 7.1$ & 0.04 \\
\hline $\mathrm{HbA}_{1 \mathrm{c}}(\%)$ & $8.2 \pm 1.8$ & $8.2 \pm 1.5$ & 0.73 \\
\hline BMI $\left(\mathrm{kg} / \mathrm{m}^{2}\right)$ & $28.3 \pm 4.8$ & $29.4 \pm 5.6$ & 0.06 \\
\hline Systolic BP (mmHg) & $137 \pm 16$ & $136 \pm 18$ & 0.52 \\
\hline Diastolic BP (mmHg) & $83 \pm 12$ & $85 \pm 13$ & 0.18 \\
\hline Total cholesterol (mmol/l) & $4.8 \pm 0.9$ & $4.8 \pm 0.9$ & 0.56 \\
\hline LDL-cholesterol (mmol/l) & $2.7 \pm 0.8$ & $2.8 \pm 0.7$ & 0.48 \\
\hline HDL-cholesterol (mmol/l) & $1.3 \pm 0.4$ & $1.3 \pm 0.4$ & 0.63 \\
\hline Triacylglycerol (mmol/l) & $1.9 \pm 1.1$ & $1.9 \pm 1.3$ & 0.64 \\
\hline C-reactive protein (mg/l) & $8.6 \pm 33.9$ & $6.2 \pm 7.5$ & 0.50 \\
\hline Current smokers (\%) & 18.9 & 21.1 & 0.56 \\
\hline Insulin therapy $(\%)$ & 18.7 & 47.5 & 0.004 \\
\hline Statin therapy $(\%)$ & 38.8 & 41.1 & 0.69 \\
\hline
\end{tabular}

IgG against p210, but not against p45, remained independently associated with the severity of coronary calcification. Follow-up CAC imaging was performed in 398 participants (age $52 \pm 8$ years, $61 \%$ male, $\mathrm{HbA}_{1 \mathrm{c}} 8 \pm 1.5 \%$ ) [30]. The mean follow-up time was $2.5 \pm 0.4$ years. Progression of $\mathrm{CAC}$ was defined as a change of $\geq 2.5$ between the square
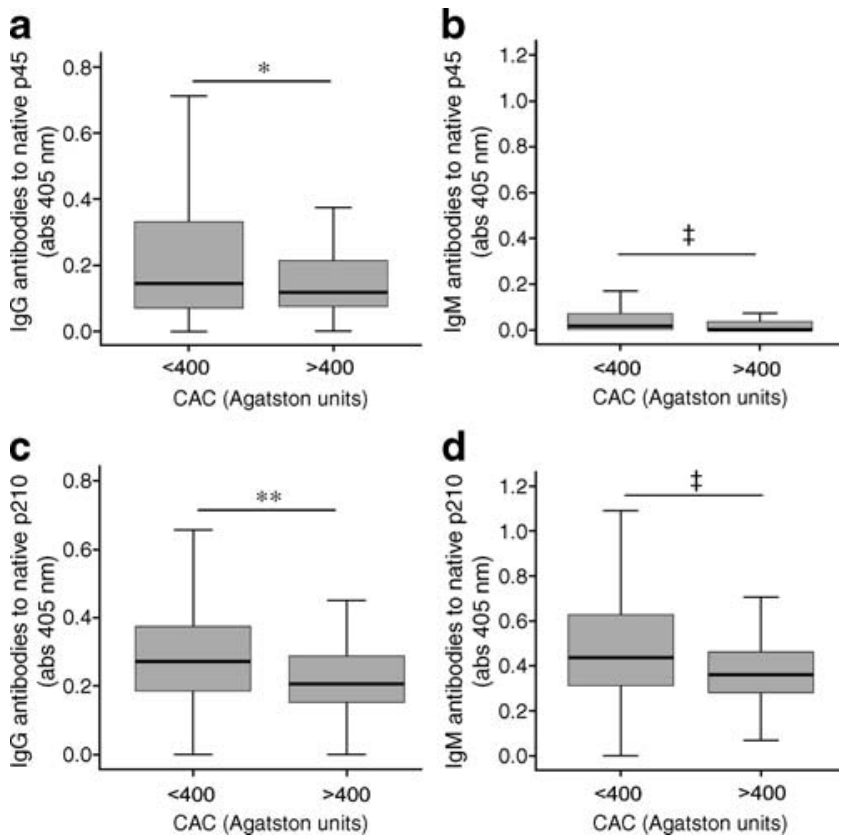

Fig. 3 Box plots showing plasma levels of a $\operatorname{IgG}$ against (absorbance [abs] units measured at $405 \mathrm{~nm}$ ) native $\mathrm{p} 45$, b IgM against native $\mathrm{p} 45$, c IgG against native p210 and $\mathbf{d} \operatorname{IgM}$ against native p210 in diabetic individuals with low to moderate ( $\leq 400$ Agatston units) and severe to extensive ( $>400$ Agatston units) coronary calcification. ${ }^{*} p<0.05$, $* * p<0.01, \$ p=0.005$ root-transformed values of baseline and follow-up volumetric scores. Patients with coronary calcium progression $(n=119)$ had lower plasma levels of IgG against native $\mathrm{p} 45$ than patients without progression $(0.19 \pm 0.21$ vs $0.29 \pm 0.33$ absorbance units, $p<0.001)$, whereas there was no association between antibodies against p210 and CAC progression. Native p210 IgG levels were significantly related to higher HDL-cholesterol and lower triacylglycerol levels, suggesting an association with good metabolic control, whereas there was no significant association between $\mathrm{IgG}$ against native p45 and age or metabolic measurements (Table 2).

During the follow-up studies, 20 events occurred (three cardiac deaths, nine non-fatal myocardial infarctions, three non-haemorrhagic strokes, four late revascularisations and one below knee amputation) [30]. No differences were observed in antibody levels between patients who suffered from a cardiovascular event and those who remained eventfree (data not shown). MPS data were available for 174 patients. There were no significant differences in antibody levels among patients with normal myocardial perfusion and those with varying degrees of myocardial ischaemia (data not shown).

\section{Discussion}

In the present study we found increased levels of $\operatorname{IgG}$ against the MDA-modified ApoB epitopes p45 and p210 in type 2 diabetes patients suffering from retinopathy and peripheral neuropathy. This suggests that oxidation of LDL may be involved in the development of diabetic microvascular complications and that autoantibodies against MDA- 
p210 represent potential biomarkers for diabetic retinopathy and peripheral neuropathy. We also demonstrate that individuals with high antibody levels against the native form of these peptides have less coronary calcification as well as less progression of coronary disease. This observation is well in line with previous studies demonstrating a lower cardiovascular risk in patients with high levels of autoantibodies against native ApoB peptides [22, 23]. Our findings provide evidence for a role of immune responses against LDL-associated antigens in diabetic complications but suggest that these may be different between micro- and macrovascular complications.

The possibility that oxidation of lipoproteins entrapped in the extracellular matrix of retinal vessels may contribute to the development of diabetic retinopathy remains largely unexplored. Oxidised LDL is proinflammatory and potentially cytotoxic for endothelial cells $[31,32]$. It may also activate autoimmune responses that cause further damage to the affected tissue [1]. Dysregulation of lipoprotein metabolism in type 2 diabetes leads to the formation of small, dense LDL particles with increased susceptibility to oxidation [33]. Accordingly, the present observation of increased levels of autoantibodies against the oxidised LDL-specific antigens MDA-p45 and MDA-p210 in patients with diabetic retinopathy is compatible with the notion that the combination of increased retinal endothelial oxidative stress and the presence of LDL particles with increased oxidation susceptibility contributes to increased local oxidation of LDL. This possibility is in line with epidemiological data demonstrating that hyperlipidaemia increases the risk of development of maculopathy in diabetes and with the observation that statin therapy may protect against the development of age-related macular degeneration [34-36]. The possibility that autoimmune responses against modified self-antigens in oxidised LDL is of functional importance for the development of diabetic retinopathy requires evaluation in appropriate animal models.

Diabetic neuropathy has many different clinical manifestations and is one of the most common complications of diabetes [37]. Like proliferative retinopathy, its severity parallels the degree and duration of hyperglycaemia and the pathophysiology is believed to involve increased intracellular stress. Its possible association with LDL oxidation remains essentially unexplored. Again, the present observations argue that this concept should be explored in appropriate animal models.

Another possibility is that the elevated levels of MDA ApoB peptide autoantibodies in patients with diabetic retinopathy and peripheral neuropathy only act as markers of the disease. There are relatively few studies of the association of oxidised LDL autoantibodies with diabetes and its complications. Festa et al. [38] have reported increased anti-oxidised LDL IgG levels in patients with type 1 diabetes compared with controls, but also that antibody levels were decreased in patients with a long duration of diabetes and high $\mathrm{HbA}_{1 \mathrm{c}}$ levels. The latter observation was explained by increased formation of oxidised LDL-specific immune complexes. An increased level of oxidised LDL-specific immune complexes has also been linked to both micro- and macrovascular complications in diabetes [39-41].

The associations between oxidised LDL autoantibodies and cardiovascular disease have been extensively studied but with inconsistent results [42-47]. The reason for this remains to be elucidated but may involve technical difficulties in standardising ELISAs based on a complex and poorly defined antigen such as oxidised LDL. One way of circumventing this problem has been to use more precisely characterised oxidised LDL antigens such as native and MDA-modified peptide fragments of ApoB [19]. The limitation of this approach is that only some of the antibodies generated against oxidised LDL are detected, but at the same time it offers the advantage of improved specificity and reproducibility. Here we demonstrate that high antibody levels against the native p45 and p210 ApoB peptides are associated with less severe coronary calcification. Moreover, we show that patients with high baseline plasma levels of native $\mathrm{p} 45 \mathrm{IgG}$ have reduced progression of coronary calcification. These observations are in good agreement with previous studies demonstrating that individuals with high levels of IgG against native p45 and p210 are at lower risk of developing acute cardiovascular events $[22,23]$. An inverse association has also been found between IgG against native p 210 and coronary atherosclerosis [23]. Studies evaluating the functional role of immune responses against native ApoB peptides have shown that immunisation of hypercholesterolaemic mice with the $\mathrm{p} 45$ and p210 peptides inhibits the development of atherosclerosis, suggesting that it may be possible to develop ApoB peptide-based vaccines for the prevention of cardiovascular disease. The present observations provide some indirect support for the notion that such vaccines could be effective also in patients with diabetes.

There has been increasing interest in identifying novel biomarkers that can be used to predict the risk of development and to monitor treatment for diabetic vascular complications. The present observations suggest that autoantibodies against the MDA-modified ApoB peptide p210 are possible biomarkers for diabetic retinopathy and peripheral neuropathy, while antibodies against the corresponding native peptides are potential biomarkers for macrovascular complications. These possibilities need to be addressed in appropriate animal models and in large prospective clinical studies. 
Acknowledgements This study was supported by grants from the Swedish Medical Research Council, the Swedish Heart-Lung foundation, the Söderberg foundation, the Albert Påhlsson foundation, the Knut and Alice Wallenberg foundation, the Malmö University Hospital foundation, the Lundström Foundation, the Crafoord Foundation, the Harrow Cardiovascular Research Trust, Michael Tabor Foundation, GE Healthcare, Bristol Myers Squibb Medical Imaging and the Derrick Smith Research Grant.

Duality of interest P. K. Shah and J. Nilsson are signed as co-inventors on patents for the use of apo B peptides in vaccines for atherosclerosis.

Open Access This article is distributed under the terms of the Creative Commons Attribution Noncommercial License which permits any noncommercial use, distribution, and reproduction in any medium, provided the original author(s) and source are credited.

\section{References}

1. Binder CJ, Chang MK, Shaw PX et al (2002) Innate and acquired immunity in atherogenesis. Nat Med 8:1218-1226

2. Hansson GK, Libby P (2006) The immune response in atherosclerosis: a double-edged sword. Nat Rev Immunol 6:508-519

3. Bjorkbacka H, Kunjathoor VV, Moore KJ et al (2004) Reduced atherosclerosis in MyD88-null mice links elevated serum cholesterol levels to activation of innate immunity signaling pathways. Nat Med 10:416-421

4. Michelsen KS, Wong MH, Shah PK et al (2004) Lack of Toll-like receptor 4 or myeloid differentiation factor 88 reduces atherosclerosis and alters plaque phenotype in mice deficient in apolipoprotein E. Proc Natl Acad Sci U S A 101:10679-10684

5. Gupta S, Pablo AM, Jiang X, Wang N, Tall AR, Schindler C (1997) IFN-gamma potentiates atherosclerosis in ApoE knock-out mice. J Clin Invest 99:2752-2761

6. Lee TS, Yen HC, Pan CC, Chau LY (1999) The role of interleukin 12 in the development of atherosclerosis in ApoE-deficient mice. Arterioscler Thromb Vasc Biol 19:734-742

7. Tupin E, Nicoletti A, Elhage R et al (2004) CD1d-dependent activation of NKT cells aggravates atherosclerosis. J Exp Med 199:417-422

8. Zhou X, Robertson AK, Rudling M, Parini P, Hansson GK (2005) Lesion development and response to immunization reveal a complex role for CD4 in atherosclerosis. Circ Res 96:427-434

9. Glass CK, Witztum JL (2001) Atherosclerosis: the road ahead. Cell 104:503-516

10. Palinski W, Witztum JL (2000) Immune responses to oxidative neoepitopes on LDL and phospholipids modulate the development of atherosclerosis. J Intern Med 247:371-380

11. Hulthe J (2004) Antibodies to oxidized LDL in atherosclerosis development — clinical and animal studies. Clin Chim Acta 348:1-8

12. Palinski W, Miller E, Witztum JL (1995) Immunization of low density lipoprotein (LDL) receptor-deficient rabbits with homologous malondialdehyde-modified LDL reduces atherogenesis. Proc Natl Acad Sci U S A 92:821-825

13. Ameli S, Hultgardh-Nilsson A, Regnstrom J et al (1996) Effect of immunization with homologous LDL and oxidized LDL on early atherosclerosis in hypercholesterolemic rabbits. Arterioscler Thromb Vasc Biol 16:1074-1079

14. Nilsson J, Calara F, Regnstrom J et al (1997) Immunization with homologous oxidized low density lipoprotein reduces neointimal formation after balloon injury in hypercholesterolemic rabbits. J Am Coll Cardiol 30:1886-1891
15. George J, Afek A, Gilburd B et al (1998) Hyperimmunization of apo-E-deficient mice with homologous malondialdehyde lowdensity lipoprotein suppresses early atherogenesis. Atherosclerosis 138:147-152

16. Zhou X, Caligiuri G, Hamsten A, Lefvert AK, Hansson GK (2001) LDL immunization induces $\mathrm{T}$ cell-dependent antibody formation and protection against atherosclerosis. Arterioscler Thromb Vasc Biol 21:108-114

17. Nilsson J, Hansson GK (2008) Autoimmunity in atherosclerosis: a protective response losing control? J Intern Med 263:464-478

18. Nilsson J, Hansson GK, Shah PK (2005) Immunomodulation of atherosclerosis: implications for vaccine development. Arterioscler Thromb Vasc Biol 25:18-28

19. Fredrikson GN, Hedblad B, Berglund G et al (2003) Identification of immune responses against aldehyde-modified peptide sequences in apo B-100 associated with cardiovascular disease. Arterioscler Thromb Vasc Biol 23:872-878

20. Fredrikson GN, Soderberg I, Lindholm M et al (2003) Inhibition of atherosclerosis in ApoE-null mice by immunization with ApoB-100 peptide sequences. Arterioscler Thromb Vasc Biol 23:879-884

21. Fredrikson GN, Andersson L, Soderberg I et al (2005) Atheroprotective immunization with MDA-modified apo B-100 peptide sequences is associated with activation of Th2 specific antibody expression. Autoimmunity 38:171-179

22. Fredrikson GN, Schiopu A, Berglund G, Alm R, Shah PK, Nilsson J (2007) Autoantibody against the amino acid sequence 661-680 in apo B-100 is associated with decreased carotid stenosis and cardiovascular events. Atherosclerosis 194:e188-e192

23. Sjogren P, Fredrikson GN, Samnegard A et al (2008) High plasma concentrations of autoantibodies against native peptide 210 of apoB-100 are related to less coronary atherosclerosis and lower risk of myocardial infarction. Eur Heart J 29:2218-2226

24. Fredrikson GN, Hedblad B, Berglund G et al (2007) Association between IgM against an aldehyde-modified peptide in apolipoprotein B-100 and progression of carotid disease. Stroke 38: $1495-1500$

25. Nilsson J, Bengtsson E, Fredrikson GN, Bjorkbacka H (2008) Inflammation and immunity in diabetic vascular complications. Curr Opin Lipidol 19:519-524

26. Anand DV, Lim E, Hopkins D et al (2006) Risk stratification in uncomplicated type 2 diabetes: prospective evaluation of the combined use of coronary artery calcium imaging and selective myocardial perfusion scintigraphy. Eur Heart J 27:713-721

27. Harding S, Greenwood R, Aldington S et al (2003) Grading and disease management in national screening for diabetic retinopathy in England and Wales. Diabet Med 20:965-971

28. Anand DV, Lahiri A, Lim E, Hopkins D, Corder R (2006) The relationship between plasma osteoprotegerin levels and coronary artery calcification in uncomplicated type 2 diabetic subjects. J Am Coll Cardiol 47:1850-1857

29. Shaw LJ, Raggi P, Schisterman E, Berman DS, Callister TQ (2003) Prognostic value of cardiac risk factors and coronary artery calcium screening for all-cause mortality. Radiology 228:826-833

30. Anand DV, Lim E, Darko D et al (2007) Determinants of progression of coronary artery calcification in type 2 diabetes role of glycemic control and inflammatory/vascular calcification markers. J Am Coll Cardiol 50:2218-2225

31. Berliner J, Leitinger N, Watson A, Huber J, Fogelman A, Navab M (1997) Oxidized lipids in atherogenesis: formation, destruction and action. Thromb Haemost 78:195-199

32. Leitinger N (2003) Oxidized phospholipids as modulators of inflammation in atherosclerosis. Curr Opin Lipidol 14:421-430

33. Krauss RM (2004) Lipids and lipoproteins in patients with type 2 diabetes. Diabetes Care 27:1496-1504 
34. Chowdhury TA, Hopkins D, Dodson PM, Vafidis GC (2002) The role of serum lipids in exudative diabetic maculopathy: is there a place for lipid lowering therapy? Eye 16:689-693

35. Chew EY, Klein ML, Ferris FL 3rd et al (1996) Association of elevated serum lipid levels with retinal hard exudate in diabetic retinopathy. Early Treatment Diabetic Retinopathy Study (ETDRS) Report 22. Arch Ophthalmol 114:1079-1084

36. Hall NF, Gale CR, Syddall H, Phillips DI, Martyn CN (2001) Risk of macular degeneration in users of statins: cross sectional study. BMJ (Clin Res Ed) 323:375-376

37. Clark CM Jr, Lee DA (1995) Prevention and treatment of the complications of diabetes mellitus. N Engl J Med 332:1210-1217

38. Festa A, Kopp HP, Schernthaner G, Menzel EJ (1998) Autoantibodies to oxidised low density lipoproteins in IDDM are inversely related to metabolic control and microvascular complications. Diabetologia 41:350-356

39. Orchard TJ, Virella G, Forrest KY, Evans RW, Becker DJ, LopesVirella MF (1999) Antibodies to oxidized LDL predict coronary artery disease in type 1 diabetes: a nested case-control study from the Pittsburgh Epidemiology of Diabetes Complications Study. Diabetes 48:1454-1458

40. Lopes-Virella MF, Virella G, Orchard TJ et al (1999) Antibodies to oxidized LDL and LDL-containing immune complexes as risk factors for coronary artery disease in diabetes mellitus. Clin Immunol 90:165-172
41. Atchley DH, Lopes-Virella MF, Zheng D, Kenny D, Virella G (2002) Oxidized LDL-anti-oxidized LDL immune complexes and diabetic nephropathy. Diabetologia 45:1562-1571

42. Lehtimaki T, Lehtinen S, Solakivi T et al (1999) Autoantibodies against oxidized low density lipoprotein in patients with angiographically verified coronary artery disease. Arterioscler Thromb Vasc Biol 19:23-27

43. Inoue $\mathrm{T}$, Uchida $\mathrm{T}$, Kamishirado $\mathrm{H}$, Takayanagi $\mathrm{K}$, Hayashi $\mathrm{T}$, Morooka S (2001) Clinical significance of antibody against oxidized low density lipoprotein in patients with atherosclerotic coronary artery disease. J Am Coll Cardiol 37:775-779

44. Tornvall P, Waeg G, Nilsson J, Hamsten A, Regnstrom J (2003) Autoantibodies against modified low-density lipoproteins in coronary artery disease. Atherosclerosis 167:347-353

45. Boullier A, Hamon M, Walters-Laporte E et al (1995) Detection of autoantibodies against oxidized low-density lipoproteins and of IgG-bound low density lipoproteins in patients with coronary artery disease. Clin Chim Acta 238:1-10

46. Rossi GP, Cesari M, de Toni R et al (2003) Antibodies to oxidized low-density lipoproteins and angiographically assessed coronary artery disease in white patients. Circulation 108:2467-2472

47. Karvonen J, Paivansalo M, Kesaniemi YA, Horkko S (2003) Immunoglobulin $M$ type of autoantibodies to oxidized lowdensity lipoprotein has an inverse relation to carotid artery atherosclerosis. Circulation 108:2107-2112 